\title{
Paroxysmal Rhinorrhea after Medullary Infarct
}

\author{
Ken Uchino Mei Lu \\ Cerebrovascular Center, Cleveland Clinic, Cleveland, Ohio, USA
}

\section{Key Words}

Wallenberg syndrome $\cdot$ Medulla $\cdot$ Cerebral infarct $\cdot$ Ischemic stroke $\cdot$ Rhinorrhea

\begin{abstract}
Lateral medullary infarction, known as Wallenberg syndrome, can be accompanied by sympathetic dysfunction. We report a case of unilateral intermittent rhinorrhea that started after an ischemic stroke in the ipsilateral lateral medulla and cerebellum. Rhinorrhea might be mediated by dysfunction of the sympathetic autonomic system.
\end{abstract}

\section{Introduction}

Infarct in the lateral medulla, resulting in the clinical syndrome called Wallenberg syndrome, is known to be associated with multitudes of peculiar symptoms in patients. Commonly encountered features are contralateral body sensory loss to pain and temperature, ipsilateral facial sensory loss, vertigo, nausea, dysphagia, hoarseness, ipsilateral ataxia, and ipsilateral Horner's syndrome with sympathetic nerve dysfunction [1]. Hiccups and inability to sneeze after lateral medullary infarct are less common [2-4]. We present a patient who developed intermittent rhinorrhea subsequent to ischemic stroke of the lateral medulla and cerebellum in the distribution of the posterior inferior cerebellar artery.

\section{Case Report}

A 74-year-old woman with atrial fibrillation, severe mitral valve regurgitation with past valve repair, coronary artery disease, hypertension, and hyperlipidemia was taken off warfarin anticoagulation in anticipation of cardiac catheterization. She then had a sudden onset of dizziness, spinning, lightheaded sensation, change in facial sensation, and horizontal diplopia. A brain MRI 4 days after onset showed an acute infarct in the right posterior inferior cerebellar artery distribution, including the right lateral medulla and inferior cerebellum (fig. 1 ).

Approximately 1 month later, the patient noticed episodes of clear secretion from her nose, with the right side more affected than the left. She felt something strange was happening to her, and she 
had a funny feeling in her throat, a runny nose with clear fluid, and sometimes tearing, but was not able to complete sneezing. This occurred 0-3 times per day lasting for 5-15 min each time, sometimes triggered by stress, showering, or walking up steps. She was perplexed by her inability to sneeze and embarrassed and disgusted by the episodic rhinorrhea.

She was evaluated by Neurology 3 months after the stroke. In addition to the intermittent rhinorrhea and inability to sneeze, her persistent symptoms included constant 'lightheadedness' and numbness of the left leg, arm, and left side of the lip. Her gait had improved to walking with a walker or cane. She no longer had diplopia. She denied any problems with swallowing or weakness during the course of her illness. On examination, she was mildly hypertensive and the functioning of her cranial nerves was notable for normal pupils and symmetric eyelids without Horner's syndrome, intact facial sensation, and intact facial, tongue and palate movements. Pinprick and temperature sensations were decreased on the left side of the body. There was also length-dependent loss of vibration and loss of pinprick sensation in the lower extremities. Coordination testing, including finger-to-nose and heel-to-shin tests, was normal. Her gait was slightly wide based. The symptoms of intermittent rhinorrhea remained unchanged at the last evaluation, 7 months after her stroke. Otolaryngological evaluation was unremarkable for other causes of rhinorrhea.

\section{Discussion}

The patient's symptom of intermittent, watery rhinorrhea lasting for minutes is unique. The lateralized rhinorrhea suggests that the underlying cause is her stroke. Chen et al. [5] reported the occurrence of contralateral rhinorrhea after a right caudate infarct. Like our patient, the rhinorrhea in the reported patient started late, 2 months after stroke, and was intermittent, but rhinorrhea was induced by mastication or swallowing. We believe that in our patient, a right lateral medullary infarct caused ipsilateral rhinorrhea due to autonomic sympathetic nerve dysfunction. Experimental unilateral extirpation of the sympathetic nerve at the superior cervical ganglion results in ipsilateral 'vasomotor rhinitis' in dogs, including 'hypersecretion of nasal glands' [6]. Rhinorrhea can be a part of the autonomic symptom of cluster headache and SUNCT (short-lasting unilateral neuralgiform headache attacks with conjunctival injection and tearing). Our patient reported no headache during the brief episodes. It is not clear why the phenomenon in our patient is intermittent or why it was delayed in onset. Internal carotid artery dissection can be associated with a clinical picture consistent with cluster headaches. In studies by Frigerio et al. [7] and Rigamonti et al. [8], three patients with carotid artery dissection had paroxysmal head pain and autonomic symptoms typical of cluster headaches, occurring several times a day and lasting from $30 \mathrm{~min}$ to $2 \mathrm{~h}$. Though the lesions in carotid artery dissections differ from those in our patient, these cases illustrate that autonomic symptoms can be intermittent after sympathetic injury. Rhinorrhea might be an underrecognized or rare complication of lateral medullary infarction. 


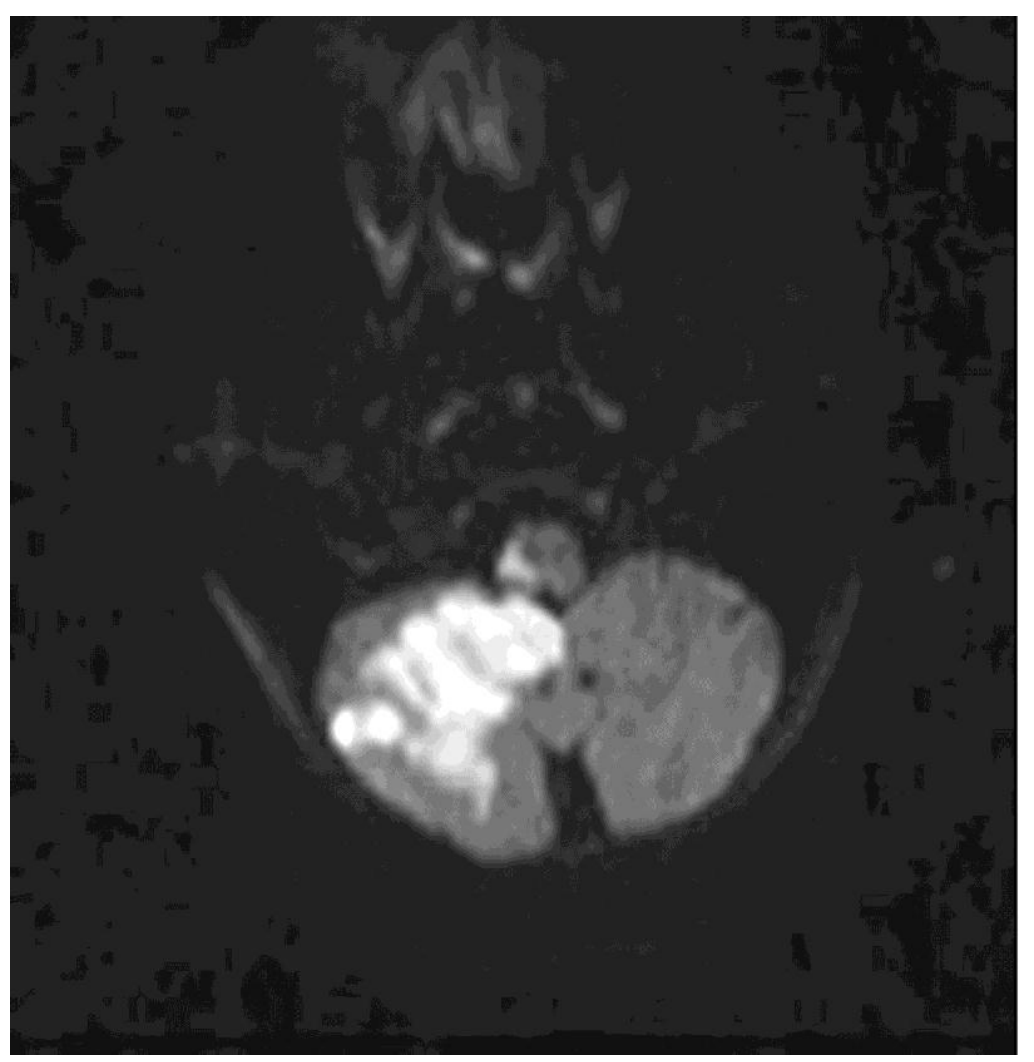

Fig. 1. Infarct involving the right lateral medulla and cerebellum.

\section{References}

1 Kim JS: Pure lateral medullary infarction: clinical-radiological correlation of 130 acute, consecutive patients. Brain 2003;126:1864-1872.

-2 Park MH, Kim BJ, Koh SB, Park MK, Park KW, Lee DH: Lesional location of lateral medullary infarction presenting hiccups (singultus). J Neurol Neurosurg Psychiatry 2005;76:95-98.

-3 Hersh M: Loss of ability to sneeze in lateral medullary syndrome. Neurology 2000;54:520-521.

-4 Seijo-Martínez M, Varela-Freijanes A, Grandes J, Vázquez F: Sneeze related area in the medulla: localisation of the human sneezing centre? J Neurol Neurosurg Psychiatry 2006;77:559-561.

5 Chen WH, Chen JJ, Lan MY: Reflex rhinorrhea after a right caudate infarct. Acta Neurol Belg 1997;97:255-257.

-6 Krajina Z, Harvey JE, Ogura JH: Experimental vasomotor rhinitis. Laryngoscope 1972;82:1068-1073.

7 Frigerio S, Bühler R, Hess CW, Sturzenegger M: Symptomatic cluster headache in internal carotid artery dissection - consider anhidrosis. Headache 2003;43:896-900.

8 Rigamonti A, Iurlaro S, Zelioli A, Agostoni E: Two symptomatic cases of cluster headache associated with internal carotid artery dissection. Neurol Sci 2007;28 (suppl 2):S229-S231. 